\title{
Demonstration of mRNA using digoxigenin labelled oligonucleotide probes for in situ hybridisation in formamide free conditions
}

\author{
G A Thomas, H G Davies, E D Williams
}

\begin{abstract}
The value of formamide for use in in situ hybridisation (ISH) for the detection of mRNA, using either single or multi probe cocktails of digoxigenin labelled oligoprobes, was investigated. Three peptides with cell specific localisation in three separate tissues-calcitonin in the thyroid, epidermal growth factor (EGF) in the submaxillary gland, and insulin in the pancreas were studied. In each case localisation was confined to the appropriate cell type, but in the presence of formamide higher concentrations of probe and a longer development time were required. The abolition of formamide from the protocol for ISH makes the technique safer, cheaper, faster and more suitable for routine diagnostic use.
\end{abstract}

(f Clin Pathol 1993;46:171-174)

Buffers for in situ hybridisation (ISH) for the demonstration of mRNA in tissue sections include formamide, ${ }^{1-3}$ a hazardous solvent. It is included because it has been shown in classic molecular biology that it reduces the temperature required for the specific annealing of probes to their target sequences. ${ }^{4}$ It has recently been suggested that detection of alkaline phosphatase labelled oligoprobes is inhibited by the use of formamide in prehybridisation and hybridisation media. ${ }^{5}$ If these findings are applicable to studies irrespective of the label used, it would simplify the technique and render it less hazardous.

We therefore studied the cell specific localisation of epidermal growth factor (EGF), calcitonin, and insulin mRNA using digoxigenin labelled oligoprobes in the presence and absence of formamide. These three peptides are immunolocalised to specific cell types within well defined areas of the tissues examined, making them ideal for investigation of the problem of non-specific binding to mRNAs other than their target sequences.

Department of Pathology, University of Wales College of Medicine, Heath Park, Cardiff CF4 4XN

G A Thomas

H G Davies

E D Williams

Correspondence to:

Dr G A Thomas,

Department of

Histopathology, University of Cambridge,

Addenbrooke's Hospital,

Hills Road, Cambridge CB2 $2 \mathrm{QG}$.

Accepted for publication

2 September 1992

\section{Methods}

Adult male Wistar rats (10 weeks of age) were sacrificed and their thyroid, pancreas, and submaxillary glands removed, and fixed by immersion in $10 \%$ neutral buffered formalin for 48 hours. After processing and embedding $5 \mu \mathrm{m}$ sections were cut and mounted on 3aminopropyltriethoxysilane coated slides and dried overnight at $60^{\circ} \mathrm{C}$. Serial sections were used for immunohistochemical staining and ISH.
Sections were incubated in either 1 in 2000 polyclonal rabbit anti-human calcitonin antibody (Dako Ltd.), 1 in 2000 polyclonal rabbit anti-insulin antibody (Europath Ltd.), or 1 in 250 polyclonal rabbit anti-mouse EGF antibody (Sigma Ltd., Poole, Dorset) at $4^{\circ} \mathrm{C}$ overnight. After washing with phosphate buffered saline, sections were incubated in peroxidase conjugated swine anti-rabbit antibody ( 1 in 100) and the peptides localised by incubation in diaminobenzidine $/ \mathrm{H}_{2} \mathrm{O}_{2}$. A positive reaction was shown as a brown deposit.

Antisense cDNA oligoprobes were used to detect calcitonin, insulin, EGF and thyroglobulin mRNA. Calcitonin and insulin were detected by cocktails of three and six individual oligoprobes, respectively. Calcitonin mRNA was localised by a mixture of two 29 mer and one 28 mer oligoprobes to human calcitonin exon 4, showing overall above $90 \%$ homology with rat calcitonin (27 of 29,25 of 29 , and 27 of 28 bases, respectively). Insulin mRNA was detected by a cocktail of six 30 mer probes to human insulin exons 1 and 2, with over $85 \%$ homology with rat insulin one and two (average of 26 and 25.5 of 30 bases, respectively).

A single 26 mer probe derived from a sequence previously used to detect rat EGF mRNA by $\mathrm{ISH}^{6}$ and a 24 polymer probe to human thyroglobulin $\mathrm{mRNA}^{3}$ were used. All probes were supplied labelled 5' with digoxigenin (British Biotechnology Products Ltd., Oxford). Cocktails of oligoprobes have been used as a method of increasing signal intensity for target mRNAs, ${ }^{7}$ and both probe cocktails (for insulin and calcitonin) were used without further modification. Preliminary experiments had also shown that signal intensity of a single oligoprobe labelled 5 ' with digoxigenin can be increased by adding a digoxigenin-11-UTP tail at the $3^{\prime}$ end by terminal transferase reaction (Thomas GA, Williams ED, unpublished observations). The two single oligoprobes to EGF and thyroglobulin supplied 5' labelled by the manufacturer were therefore modified by $3^{\prime}$ end labelling to increase signal intensity. The amplification of signal found by the use of either a cocktail of probes or the double ended labelling is presumably related to an increase in the number of antibody binding sites hybridised per copy of mRNA, and possibly also due to a greater local concentration of enzyme facilitating formazan deposition.

The hybridisation technique used a standard protocol adapted from Farqharson et al. ${ }^{2}$ Preliminary experiments to study the effect of proteinase $\mathrm{K}$ digestion on signal intensity for 
each target mRNA were carried out and an empirical optimum of $3 \mu \mathrm{g} / \mathrm{ml}$ proteinase $\mathrm{K}$ for 30 minutes at $37^{\circ} \mathrm{C}$ was used. Sections were also preincubated in hybridisation buffer containing $4 \times$ sodium citrate, sodium chloride (SSC), $0.5 \%$, bovine sodium albumin $0.5 \%$ Ficoll, $0.5 \%$ PVA, $100 \mu \mathrm{g} / \mathrm{ml}$ salmon sperm DNA, $5 \mathrm{mg} / \mathrm{ml}$ sodium pyrophosphate in $5 \mathrm{mM}$ TRIS- $\mathrm{HCl}$, pH 7.5 (all reagents from Sigma Ltd., Poole, Dorset), with or without $50 \%$ formamide. Hybridisation was carried out overnight at $42^{\circ} \mathrm{C}$ in humidity chambers using either labelled calcitonin probe $(0.15,0.3$ and $0.6 \mathrm{ng} / \mu \mathrm{l})$, insulin probe $(0.1,0.2$, and $0.3 \mathrm{ng} / \mu \mathrm{l})$ or EGF probe $(0.2$, 0.5 , and $2.5 \mathrm{ng} / \mu \mathrm{l}$ ) in $45 \mu \mathrm{l}$ of the same hybridisation buffer used for the prehybridisation step. The concentrations quoted for the cocktail probes for calcitonin and insulin are the total probe concentration, that is, $0.15 \mathrm{ng} / \mu \mathrm{l}$ of calcitonin probe represents 0.05 $\mathrm{ng} / \mu \mathrm{l}$ for each of the three probes contained in the mixture. Controls comprised: (a) pretreatment with $100 \mu \mathrm{g} / \mathrm{ml}$ RNAse A (Sigma Ltd., Poole, Dorset) in $2 \mathrm{xSSC} / 10 \mathrm{mM} \mathrm{Mg}$ $\mathrm{Cl}_{2}$ for two hours at $37^{\circ} \mathrm{C}$ prior to hybridisation with the relevant probe; (b) hybridisation with irrelevant probe (thyroglobulin $0.3 \mathrm{ng} / \mu \mathrm{l}$ or calcitonin probe cocktail $0.6 \mathrm{ng} / \mu \mathrm{l}$ ); or (c) omission of labelled probe. Sections were washed in decreasing concentrations of SSC, and the bound probe detected by immunohistochemistry for digoxigenin, using nitroblue tetrazolium chloride (NBT) and bromochloroindoylphosphate (BCIP) for localisation of bound alkaline phosphate labelled antibody. The final detection step (incubation in BCIP/NBT) was carried out for either two hours or overnight. A positive reaction was indicated by deposition of blue diformazan.

\section{Results}

\section{CALCITONIN}

After incubation in BCIP/NBT overnight, ISH using the calcitonin cDNA probe cocktail showed a clear localisation to individual cells lying in a parafollicular position in the central area of the thyroid lobe whether or not formamide was present in the hybridisation medium. Serial sections showed that these cells were strongly positive for calcitonin peptide or immunocytochemical staining. No reaction product was observed with ISH in the adjacent follicular epithelium or stroma whether sections were hybridised in formamide containing or formamide free media (figs $1 \mathrm{~A}-\mathrm{C}$ ). The reaction product was clearly localisable at all concentrations of probe used $(0.6,0.3$, or $0.15 \mathrm{ng} / \mu \mathrm{l})$, irrespective of the hybridisation media.

When the shorter two hour incubation in BCIP/NBT was used, however, a strong positive reaction was observed in $\mathrm{C}$ cells hybridised in formamide free medium with the two higher concentrations of probe cocktail. In contrast, when hybridisation was carried out in formamide containing medium, reaction product was barely visible, even at the highest concentration of probe cocktail used. Sections pretreated with RNase were negative on ISH with calcitonin probe. Thyroglobulin showed the expected distribution in follicular cells, with considerable intercellular and interfollicular heterogeneity.

\section{INSULIN}

After overnight incubation in BCIP/NBT, a positive reaction with ISH was observed only in the islet cells of the rat pancreas, not in the acini, when sections were hybridised in either medium. Very low concentrations of probe $(0.1 \mathrm{ng} / \mu \mathrm{l})$ and hybridisation in formamide containing medium gave weak results even after overnight incubation in BCIP/NBT; the signal in sections hybridised in formamide free media was much stronger. As expected, immunolocalisation of insulin peptide was only observed in the islet cells of the rat pancreas.

When the duration of incubation in BCIP/NBT was reduced to two hours, there was only very weak localisation of insulin mRNA in sections hybridised in formamide containing medium. Hybridisation in formamide free medium resulted in easily detectable signals for bound probe at all con-

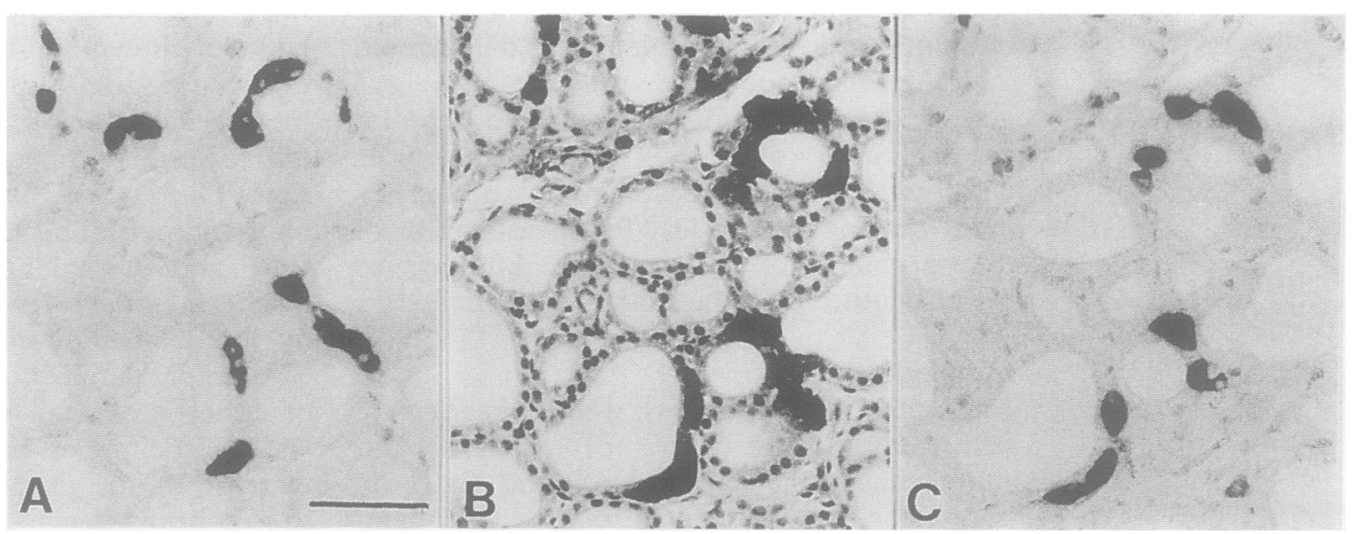

Figures 1A-C Calcitonin $m R N A$ and peptide in serial sections of rat thyroid. The scale bar represents $50 \mu m$.

$1 A$ Histochemical demonstration of digoxigenin labelled probe cocktail bound to calcitonin $m R N A(0.6 \mathrm{ng} / \mu \mathrm{l})$ in thyroid $C$ cells after hybridisation in formamide containing medium and overnight incubation in NBT/BCIP.

$1 B$ Immunohistochemistry for calcitonin peptide in thyroid $C$ cells.

1C Histochemical demonstration of calcitonin mRNA using the same technique as that used for Fig $1 A$, but in the absence of formamide.

The distribution and intensity of $m R N A$ signal is identical in both sections used for ISH. 


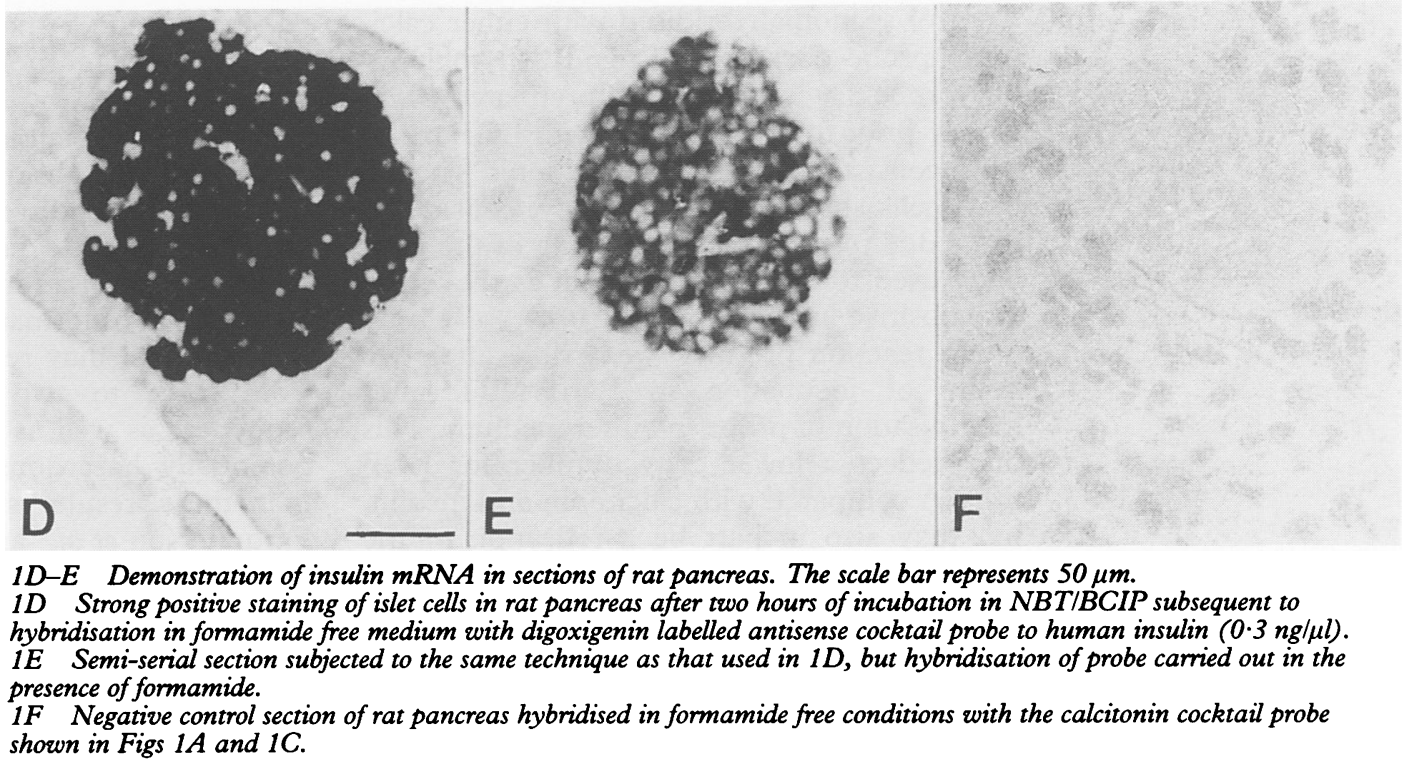

centrations and time points studied (figs 1D and E). Sections pretreated with RNAse, hybridised with irrelevant probe (fig $1 F$ ) or in the absence of probe were consistently negative, irrespective of the time of incubation in BCIP/NBT.

EGF

Overnight incubation of sections hybridised with EGF probe resulted in localisation of EGF mRNA to the granular and striated ductal cells of the rat submaxillary gland. EGF peptide, localised by immunohistochemical staining showed a similar distribution, and both mRNA and peptide showed consider-

able intercellular variation in content. However, strong immunoreactivity did not always correlate with high mRNA content (figs $2 \mathrm{~A}$ and $\mathrm{B}$ ). The distribution of signal was identical whether or not the hybridisation media contained formamide. However, the technique without formamide seemed to be more sensitive. EGF mRNA was only just localisable at a probe concentration of $0.5 \mathrm{ng} / \mu \mathrm{l}$ after overnight incubation in BCIP and NBT when formamide had been present in the hybridisation medium; it was clearly localisable at both $0.5 \mathrm{ng} / \mu \mathrm{l}$ and $0.2 \mathrm{ng} / \mu \mathrm{l}$ when sections had been Hybridised in formamide free medium (figs 2C and $\mathrm{D}$ ).

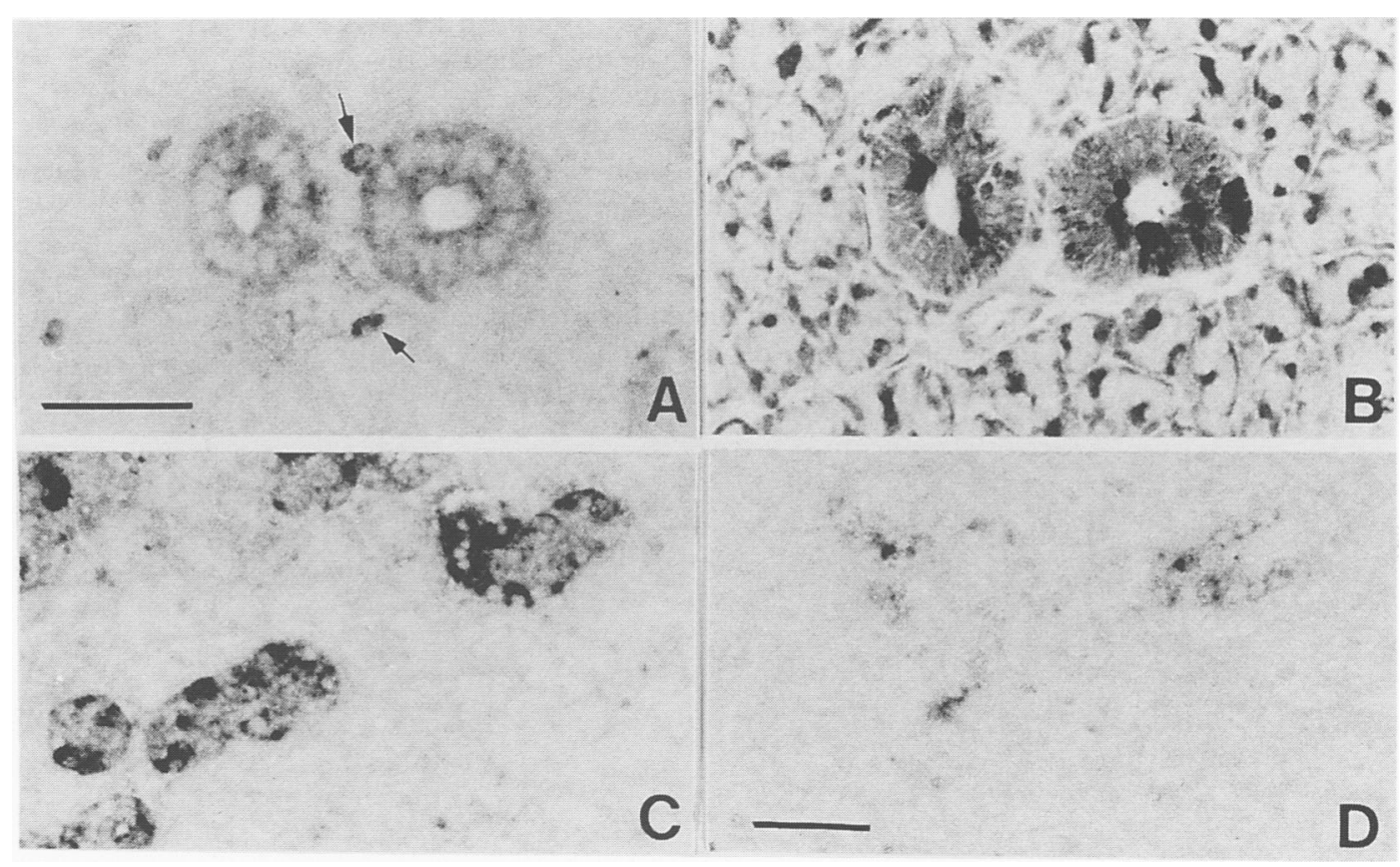

Figure 2A ISH for EGF in rat submaxillary gland using formamide free conditions. A low level of $m R N A$ is observed in this ductal epithelium. The positive reaction observed in mast cells (arrowed) is due to non-specific binding of antibody to digoxigenin as this reaction was also observed in control sections.

$2 B$ Serial section to fig $2 A$ showing strong cell localisation of EGF peptide in ductal epithelial cells of rat submaxillary gland contrasting with the low $\mathrm{mRNA}$ content in this particular duct.

$2 C$ ISH for EGF $m R N A$ in another area of the section shown in fig $2 A$, showing strong positivity in ductal epithelium. $2 D$ Semi-serial section to fig $2 C$ hybridised with the same probe at the same concentration in formamide containing medium. Although the distribution of the signal is the same as in $2 C$, the reaction is very much weaker.

The scale bars represent $50 \mu \mathrm{m}$. 
Control sections hybridised with either calcitonin probe cocktail $(0.6 \mathrm{ng} / \mu \mathrm{l})$, thyroglobulin probe $(0.3 \mathrm{ng} / \mu \mathrm{l})$, or pretreated with RNase prior to hybridisation with EGF probe were consistently negative. Scattered stromal mast cells showed ISH positivity, considered to be due to non-specific binding of the antibody used to detect digoxigenin as they were also positive in no probe controls.

No reaction product was visible after two hours of incubation in BCIP/NBT after hybridisation of probe in either medium. This may reflect a lower copy number for EGF mRNA compared with calcitonin and insulin, but may also in part be a reflection of the increased sensitivity of the ISH technique when cocktails of oligoprobes are used.

\section{Discussion}

ISH can be successfully used in the absence of formamide with a simplified technique using very low concentrations of digoxigenin labelled oligoprobes. The presence of formamide in the hybridisation medium also provided good results, but required the use of higher concentration of probe and prolonged incubation in BCIP/NBT to detect the target mRNA sequence. With all three probes, whether formamide was absent or present, the pattern of localisation was the same and reaction product was localised only to the cell containing the target mRNA, and there was no relevant background non-specific staining of other cells within the same tissue with either of the two media used, apart from the minor problem of mast cells in the submaxillary gland, present whether formamide was used or not. Substitution of the test probe with an irrelevant probe also produced negative results, showing that the staining observed was sequence specific.

We studied these three mRNA species as they are known to be localised only to individual cell types forming the minority of cells within particular tissues. The observed increase in signal intensity in the formamide free medium was not accompanied by either a general increase in overall background staining or by staining of any other type of cells.
All localisation remained specific to cells of the appropriate morphology for the probe used, supported by localisation by immunohistochemical staining whether formamide was present or absent. This shows that with the in situ hybridisation technique used, the lack of formamide did not affect the specificity of the hybridisation.

Abolition of formamide from the hybridisation protocol may result in a time reduction from three to two days for some target sequences as well as eliminating the use of a potentially hazardous chemical. We believe that these results support the findings of Farquharson et $a l,{ }^{5}$ and show that formamide is not necessary for, and may indeed reduce the sensitivity of, detection of bound non-isotopic oligoprobes, irrespective of the label used. Furthermore, the ability to decrease the concentration of oligoprobe needed in the hybridisation medium under formamide free conditions, thus reducing the cost of the procedure, has important implications in the routine implementation of this technique in diagnostic pathology departments.

We thank British Biotechnology Products Ltd, for the gift of the insulin probe, Mr P Langham for photography, and the Medical Research Council for financial support.

1 Pringle JH, Primrose L, Kind CN, Talbot IC, Lauder I. In situ hybridization demonstration of poly-adenylated RNA sequences in formalin-fixed paraffin sections using a biotinylated oligonucleotide poly $\mathrm{d}(\mathrm{T})$ probe. $\mathcal{F}$ Pathol 1989;158:279-86.

2 Farquharson M, Harvie R, McNichol AM. Detection of messenger mRNA using a digoxigenin end labelled messenger mRNA using a digoxigenin end labelled oligodeoxy

3 Ismail SM, Thomas GA, Ghandour FA, Davies HG, Attanoos R, Williams ED. Oestrogen receptor protein and $\mathrm{mRNA}$ in adenocarcinoma of the uterine cervix. $\mathrm{Br}$ 7 Cancer 1992; (in press)

4 Sambrook J, Fritsch EF, Maniatis T. Molecular cloning. $A$ laboratory manual. New York: Cold Spring Harbour Laboratory Press, 1989.

5 Farquharson MA, Harvie R, Kenndy A, McNichol AM. Detection of mRNA by in situ hybridization and in Northern blot analysis using oligodeoxynucleotide
probes labelled with alkaline phosphatase. $\mathcal{F}$ Clin Pathol. 1992;45:999-1002.

6 Couwenhoven R, Luo W, Snead ML. Co-localisation of EGF transcripts and peptides by combined immunohistochemistry and in situ hybridisation. $\mathcal{f}$ Histochem Cytochem 1990;38:1853-7.

7 Pringle JH, Rupral AK, Primrose L, In situ hybridisation of immunoglobulin light chain mRNA in paraffin sections using biotinylated or hapten-labelled oligonucleotide probes. F Pathol 1990;162:197-207. 